\title{
Relation between laboratory cantilever bending test and finite element analysis of five different nickel-titanium rotary instruments
}

\author{
Amira Galal Ismail ${ }^{1}$, Manar Galal ${ }^{1}$, Mohamed H. Zaazou ${ }^{1}$, Tamer M. Hamdy ${ }^{1 *}$ (10 and Rasha M. Abdelraouf ${ }^{2}$
}

\begin{abstract}
Background: Flexibility during bending is a critical feature that influences the performance and safety of endodontic nickel-titanium rotary instruments. Flexibility of the endodontic files could be assessed via laboratory test or indicated theoretically by finite element analysis (FEA). The aim of the study is to determine the cantilever load required for bending five different nickel-titanium (NiTi) rotary instruments (laboratory test) and to calculate maximum von Mises stresses due to bending moment and vertical displacement (deflection) (theoretically by FEA) and compare both results.
\end{abstract}

Results: TF Adaptive file demonstrates the least cantilever load required for bending, the least von Mises stresses generated and the highest deflection of the endodontic files. Contrary, One Shape file reported the highest cantilever load required for bending, the highest von Mises stresses generated and the least deflection among all the tested endodontic files.

Conclusion: The finite element analysis validated the results of the laboratory cantilever bending test for the examined nickel-titanium rotary instruments.

Keywords: Rotary files, NiTi, Design, Stress distribution, Bending, Flexibility, Deflection, Cantilever bending test, Finite element analysis

\section{Background}

The most important objectives of endodontic treatment are to obtain a perfect clean well-shaped root canal and to preserve the root canal anatomy without inducing iatrogenic insults such as ledge formation, canal transportation, or even perforation (Sihivahanan et al. 2017).

The rotational movement of the NiTi rotary instruments inside curved root canals generate both tensile and compressive stresses throughout the sides of the instrument, which should be minimized (Gao et al.

\footnotetext{
* Correspondence: dr tamer hamdy@yahoo.com

${ }^{1}$ Restorative and Dental Materials Department, National Research Centre (NRC), El Bohouth St., 12622 Dokki, Giza, Egypt

Full list of author information is available at the end of the article
}

2011). Prevention of instruments fracture during the treatment procedure is mandatory to avoid undesirable clinical situation (Poly et al. 2019). Flexibility during bending and fracture resistance are crucial properties affecting the performance and longevity of the ideal nickel-titanium (NiTi) endodontic rotary instruments (He and Ni 2010; Arbab-Chirani et al. 2011).

Using a flexible NiTi rotary instruments permits their bending ability inside curved canals with minimal load creation. Moreover, it influences the possibility of endodontic file separation (Fukumori et al. 2018). Modifications of the flexibility of the NiTi endodontic rotary instruments depend greatly on their metallurgical composition, fabrication procedure, manufacturing treatment, and geometrical design (He and Ni 2010; Hamdy

\section{Springer Open}

(๑) The Author(s). 2020 Open Access This article is licensed under a Creative Commons Attribution 4.0 International License, which permits use, sharing, adaptation, distribution and reproduction in any medium or format, as long as you give appropriate credit to the original author(s) and the source, provide a link to the Creative Commons licence, and indicate if changes were made. The images or other third party material in this article are included in the article's Creative Commons licence, unless indicated otherwise in a credit line to the material. If material is not included in the article's Creative Commons licence and your intended use is not permitted by statutory regulation or exceeds the permitted use, you will need to obtain permission directly from the copyright holder. To view a copy of this licence, visit http://creativecommons.org/licenses/by/4.0/. 
et al. 2019; Galal and Hamdy 2020). Cantilever bending test is the most frequently used test to evaluate the flexibility of the endodontic rotary instruments (Fukumori et al. 2018). The mechanical properties are diverse among the different types of NiTi rotary instruments (Arbab-Chirani et al. 2011).

The NiTi rotary instruments deform permanently when subjected to stresses that exceed the material yield strength with subsequent separation. The increased von Mises stress influences the prospect of instrument segmental separation and consequence failure upon frequent use. It was observed that the stresses upon the NiTi instruments increased with increasing their stiffness (Versluis et al. 2012). Pongione et al. concluded that the increase in $\mathrm{Ni}-\mathrm{Ti}$ rotary instruments' stiffness results in more stress concentration; therefore, the risk of fatigue failure will increase (Pongione et al. 2012). The displacement of file due to the moment applied to the NiTi rotary instruments varied with the load and bending stiffness linearly (E. et al. 2003).

The FEA approach could be applied to analyze numerically the mechanical behavior of the endodontic instruments. This approach requires construction of a distinct model which coincide with the structure to be investigated and of the mechanical features and composition of the used material; moreover, the environmental conditions should be fixed (E. et al. 2003). The use of FEA investigational method to evaluate the mechanical performance of the dental $\mathrm{NiTi}$ instruments appeared to be relevant (Arbab-Chirani et al. 2011).

The behavior of cantilever bending could be simulated in FEA by applying a bending moment to the constructed models and calculating the created equivalent stresses which denotes the three-dimensional stresses condition with a single value, which is called von Mises stress distribution (E. et al. 2003). Moreover, bending displacement (deflection) which is $3 \mathrm{~mm}$ from the instrument tip could be also evaluated (Kim et al. 2009a).

Even though FEA is commonly used in the endodontic field to investigate the performance of the NiTi rotary instruments under bending circumstances (Baek et al. 2011; Fu et al. 2019), but up till now a great demand is needed to evaluate the relation between the results of bending the endodontic rotary NiTi instrument experimentally and theoretically by FEA as no previous study compared them.

Therefore, the purpose of the current study was to evaluate the relation between the laboratory cantilever bending test finding and numerical maximum von Mises stresses due to bending moment and deflection values from finite element analysis of five different NiTi rotary instruments.

\section{Methods}

\section{Laboratory assessment}

The cantilever bending test of five different brands of NiTi rotary instruments were measured using Universal testing machine (Model 3345; Instron Industrial Products, Norwood, MA, USA) to evaluate their flexibility laboratory. The NiTi instruments were divided into five groups $(n=8)$. All the selected NiTi rotary instruments were with $25-\mathrm{mm}$ length, size 25 , and 0.06 taper (Table 1 ).

Cantilever bending induced at a load-cell of $5 \mathrm{kN}$. The NiTi rotary instrument specimen was horizontally griped by the tightening screws of the Universal testing machine. The tip of the specimen was subjected to deflection $\left(45^{\circ}\right)$ using mono-beveled chisel attached to the machine upper compartment at crosshead speed $(0.5 \mathrm{~mm} / \mathrm{min})$. The chisel hit the specimen at $3 \mathrm{~mm}$ from the tip of the file as shown in Fig. 1 . The maximum load required to bend the specimen was recorded in gram.

\section{Creation of 3-dimensional finite element models}

The digitized models of the five brands of NiTi rotary instruments (TF adaptive, HyFlex EDM, Wave one, Reciproc Blue, and One Shape) were created through image processing from real-sized scanning of the actual NiTi rotary instruments via computerized tomography (CT) and stereomicroscope scanning(M. Galal, T. Nassef, S. Saber, M. Zaazou 2015). The C.T. images were obtained using Multi Slice C.T 64 machine (Model GE Discovery VCT, Germany) at $120 \mathrm{kV}$ and $250 \mathrm{~mA}$ with thickness slice of $0.4 \mathrm{~mm}$. The NiTi rotary instruments were imaged by a stereomicroscope (Technival 2, Carlzeiss JENA) at magnifications $(\times 5, \times 10$, and $\times 16)$ to attain the detailed shape.

The collected digitalized images for each file such as cross section, working length, taper, number of flutes, and tip's diameter were utilized to drawn in two-dimensional (2D) models using Computer Aided Design programs (CAD) (SolidWorks software package). The 2D file with (.prt) extension was converted into Stereolithographic (.stl) extension to be readable by MATLAB (MathWorks, Inc., Natick, Massachusetts, USA) software. Building of three-dimensional (3D) model in the form of sections was achieved by MATLAB software using the previous collected imaged data. The 3D models and meshing of the simulated NiTi rotary instruments were done using SolidWorks software (SolidWorks Corp., USA).

\section{Finite element analysis assessment}

The assessment of the flexibility of the different finite element models was evaluated mathematically under 
Table 1 The NiTi rotary instruments tested

\begin{tabular}{llll}
\hline Brand name & Manufacturer & Length & Lot No. \\
\hline TF Adaptive & SybronEndo, Orange, CA, USA & 25 & 051638929 \\
Hyflex EDM & Coltene/Whaledent, Altstatten, Switzerland & 25 & H34710 \\
Wave one & Dentsply Maillefer, Ballaigues, Switzerland & 25 & 1098369 \\
Reciproc Blue & VDW, Munich, Germany & 25 & 041332 \\
One Shape & Micro-Mega, Besancon Cedex, France & 25 & 17100107 \\
\hline
\end{tabular}

cantilever bending simulated conditions by applying a constant load of $1 \mathrm{~N}$ at $3 \mathrm{~mm}$ from the instrument tip (Kim et al. 2009b). The shaft rigidly held in place. Both von Mises stress distribution and vertical displacement (deflection) were recorded in $\mathrm{MPa}$ and $\mathrm{mm}$ respectively.

\section{Statistical analysis}

Statistical analysis was conducted for the laboratory cantilever bending test. A one-way analysis of variance (ANOVA) and a Tukey HSD test were used to perform the statistical analysis using IBM $^{\bullet}$ SPSS $^{\oplus}$ Statistics Version 20 software (SPSS Inc., IBM Corporation; USA). The level of significance was set at $5 \%(P<0.05)$.

\section{Results}

\section{Laboratory cantilever bending test}

Statistical analysis of mean and standard deviation values of the cantilever bending test measured by calculation of the required load to bend the $\mathrm{NiTi}$ endodontic instruments to $45^{\circ}$ is presented in Table 2 and Fig. 2.

The laboratory finding of the tested endodontic instrument revealed that the TF Adaptive required the least load for cantilever bending (most flexible) (86 g), while the One Shape needed the maximum load for cantilever bending (most stiff) (174 g). The cantilever bending load of the files arranged in an ascending order (g): TF Adaptive (86), HyFlex EDM (99.8), Wave One (144.5), Reciproc Blue (155), and One Shape (174). There was a significant difference between the cantilever bending load among the various endodontic files.

\section{Finite element analysis}

\section{Maximum von Mises stress distribution}

The von Mises stresses during bending by FEA are shown in Figs. 3, 4, 5, 6, and 7. The TF Adaptive showed the least von Mises stresses (most flexible) $(471 \mathrm{MPa})$, while the One Shape showed the maximum von Mises stresses (most stiff) (1368 MPa). The von Mises stresses of the examined files arranged in an ascending order (MPa): TF Adaptive (471), HyFlex EDM (537), Wave One (583), Reciproc Blue (777), and One Shape (1368). Comparison of the von Mises stress results summarized in bar chart is presented in Fig. 8.

\section{Deflection}

The FEA results of the deflection (displacement) displayed that the TF Adaptive showed the maximum deflection (most flexible) $(9 \mathrm{~mm})$, while the One Shape showed the least deflection $(1.4 \mathrm{~mm})$ (most stiff). The deflection of the tested files arranged in an ascending order (mm): One Shape (1.4), Reciproc Blue (2.3), Wave
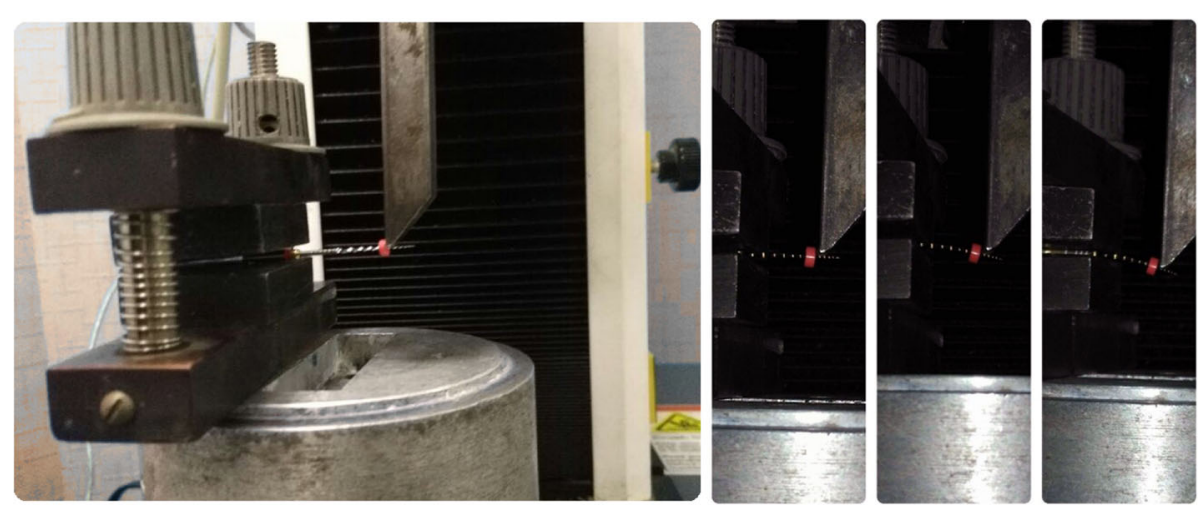

Fig. 1 Laboratory cantilever bending test of NiTi instrument 
Table 2 Mean and standard deviation of laboratory cantilever bending test

\begin{tabular}{|c|c|c|c|c|c|c|c|c|c|c|c|}
\hline \multirow{2}{*}{$\frac{\text { Endodontic file }}{\text { Cantilever bending (grams) }}$} & \multicolumn{2}{|c|}{ TF adaptive } & \multicolumn{2}{|c|}{ HyFlex EDM } & \multicolumn{2}{|c|}{ Wave One } & \multicolumn{2}{|c|}{ Reciproc Blue } & \multicolumn{2}{|c|}{ One Shape } & \multirow{2}{*}{$\frac{P \text { value }}{<0.0001^{*}}$} \\
\hline & Mean & SD & Mean & SD & Mean & SD & Mean & SD & Mean & SD & \\
\hline & $86^{\mathrm{a}}$ & \pm 0.1 & $99.8^{\mathrm{b}}$ & \pm 0.5 & $144.5^{c}$ & \pm 0.4 & $155^{d}$ & \pm 0.8 & $174^{e}$ & \pm 0.4 & \\
\hline
\end{tabular}

Mean with different letters indicate statistically significance difference. *Significant $(p<0.05)$

One (4.5), HyFlex EDM (5.9), and TF Adaptive (9). Comparison of the deflection results summarized in bar chart is presented in Fig. 9.

Finally, the least cantilever load required for bending, the least von Mises stresses generated, and the highest deflection of the endodontic file were detected by using (TF Adaptive). Contrary, the highest cantilever load required for bending, the highest von Mises stresses generated and the least deflection of the endodontic file were detected by using One Shape. Table 3 and Fig. 10 summarize the results obtained from both laboratory cantilever bending test and numerical FEA during bending.

\section{Discussion}

The flexibility of NiTi rotary instruments is a decisive requirement for successful root canals treatment, particularly in curved root canals (Gavini et al. 2018). The alloy properties of NiTi rotary instruments dominate their flexibility (Elnaghy and Elsaka 2015). The flexibility is frequently evaluated in the laboratory using cantilever bending resistance test (Zhou et al. 2013). Experimentally, the maximum load required for displacement of the NiTi instrument under cantilever bending moment is a measure of instrument's stiffness. The less the load required to bend the endodontic file indicates the file is more flexible (Kim et al. 2009b).

FEA is a numerical reliable tool to evaluate the stress distribution analyses in the NiTi rotary instruments (Zaazou et al. 2012; Jiang et al. 2018). Moreover, FEA permits the study of each feature individually under controlled conditions. It also allows investigation of different variables that is so difficult to be inspected experimentally (Versluis et al. 2012). Versluis et al. reported that the NiTi rotary instruments' stiffness influences the creation of the internal stresses (Versluis et al. 2012). Deflection under bending reproduces the instrument's flexibility (Galal et al. 2019).

Even though FEA is considered a precisely controlled study, Baek et al. reported that the theoretical FEA results might differ from that of the experimental actual test which may be attributed to the manufacturing methods, surface defects (Baek et al. 2011).

In this study, the relation between the laboratory test and numerical procedure FEA of the rotary NiTi endodontic instrument was evaluated. There is a close relation between the laboratory cantilever bending results and FEA finding gained from both von Mises stress

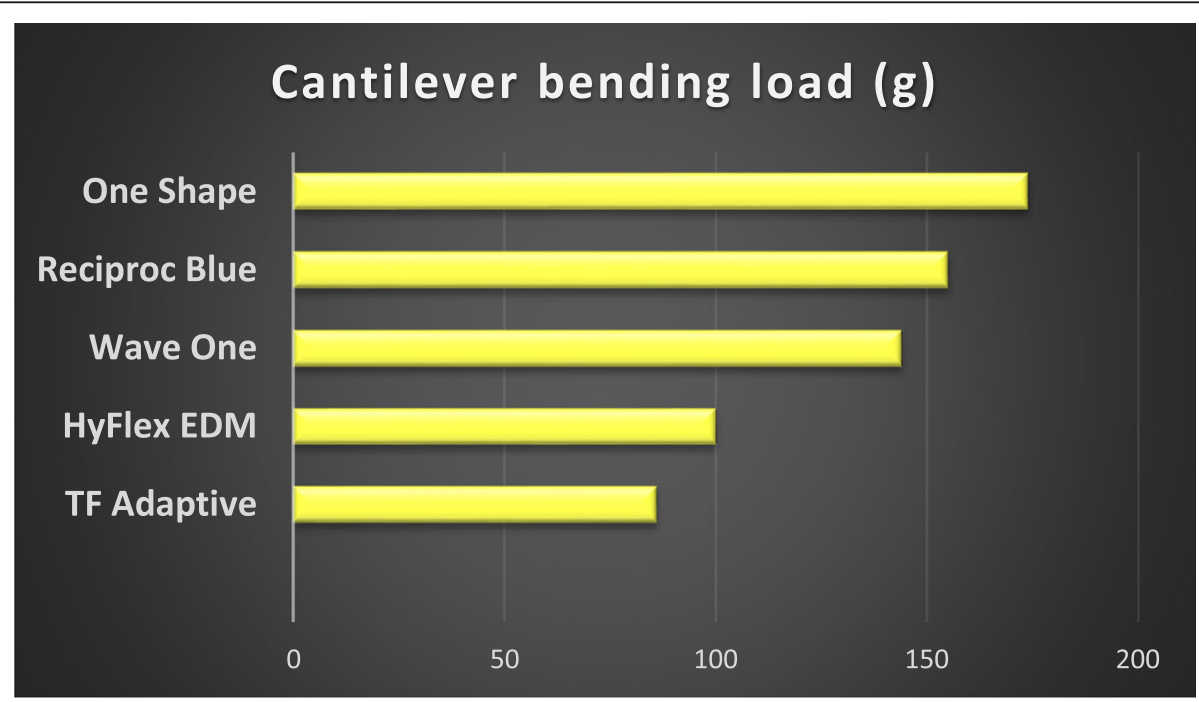

Fig. 2 Bar chart showing cantilever bending load among the different endodontic instruments 


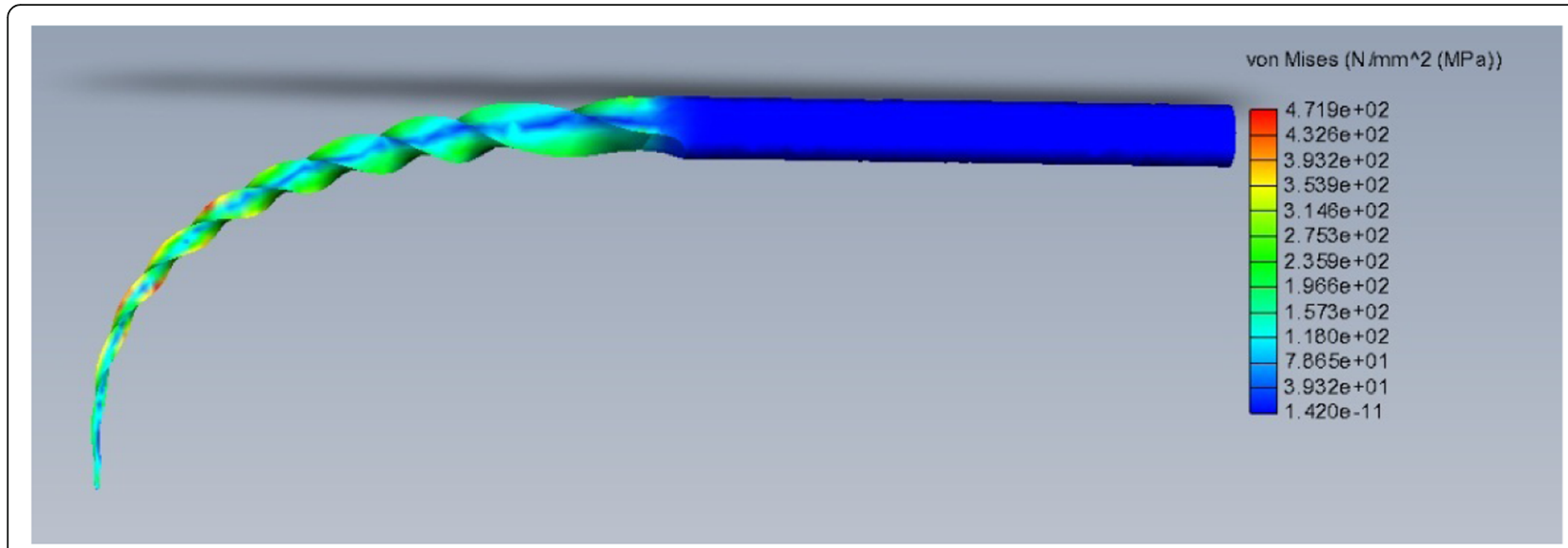

Fig. 3 Von Mises stresses during bending by FEA of TF Adaptive file

distribution and displacement under bending. The matching between laboratory cantilever bending and FEA finding comes in agreement with Lee et al., yet the cyclic fatigue fracture resistance was evaluated in that research (Lee et al. 2011).

The laboratory and numerical finding of TF Adaptive file demonstrate the least cantilever load required for bending, the least von Mises stresses generated, and the highest deflection of the endodontic files which denote their highest flexibility. This finding may be attributed to the metallurgical composition of the file which is based in their fabrication on the transformation of austenite $\mathrm{NiTi}$ wire into the $\mathrm{R}$ phase by thermal procedure (De Arruda Santos et al. 2013). Moreover, the twisting of the file give a unique shape that improve file flexibility (Walid 2017; Hamdy et al. 2019).

Contrary, One Shape file reported the highest cantilever load required for bending, the highest von Mises stresses generated and the least deflection among all the tested endodontic files hence decreased flexibility. This may be due to its asymmetrical design with large core diameter which decrease the flexibility of the file (Elnaghy and Elsaka 2015); in addition, the instrument was manufactured through machine grinding to from a conventional austenite (55-NiTi alloy) (Karova 2015).

Thus, the lower the flexibility of the file and the higher cantilever load required for bending were observed; this may produce higher von Mises stress with minimal deflection.

\section{Conclusions}

The finite element analysis validated the results of the laboratory cantilever bending test for the examined nickel-titanium rotary instruments. The cantilever bending load varied directly with von Mises stress and inversely with the file deflection and flexibility.

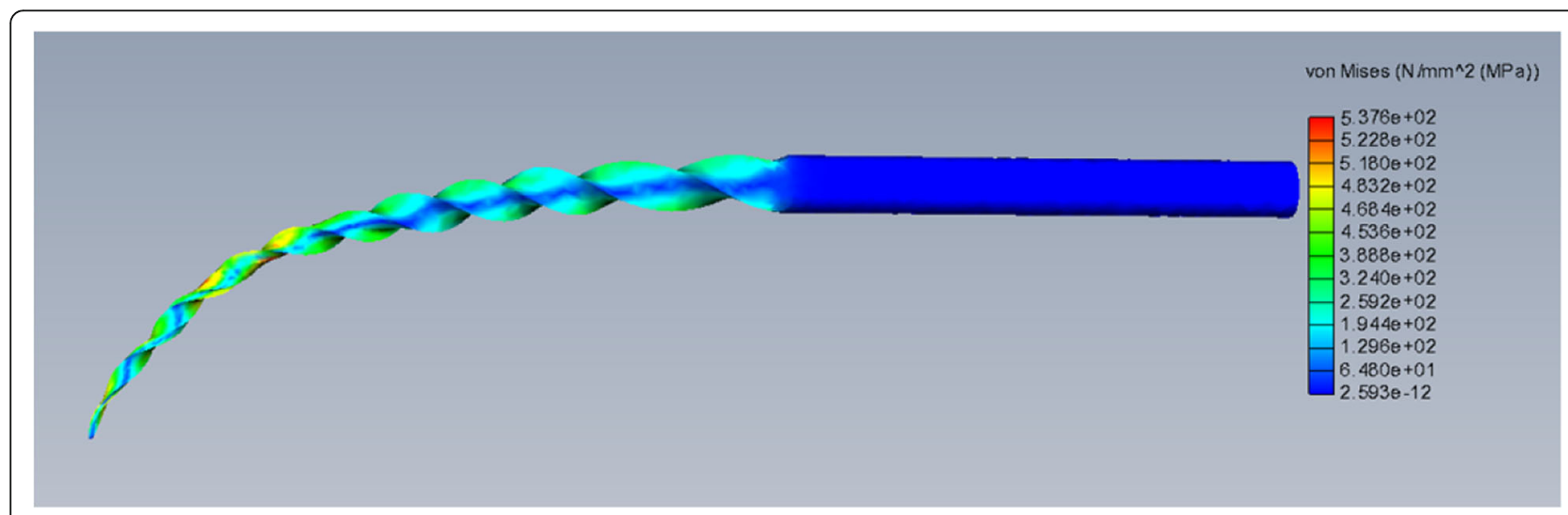

Fig. 4 Von Mises stresses during bending by FEA of Hyflex EDM file 

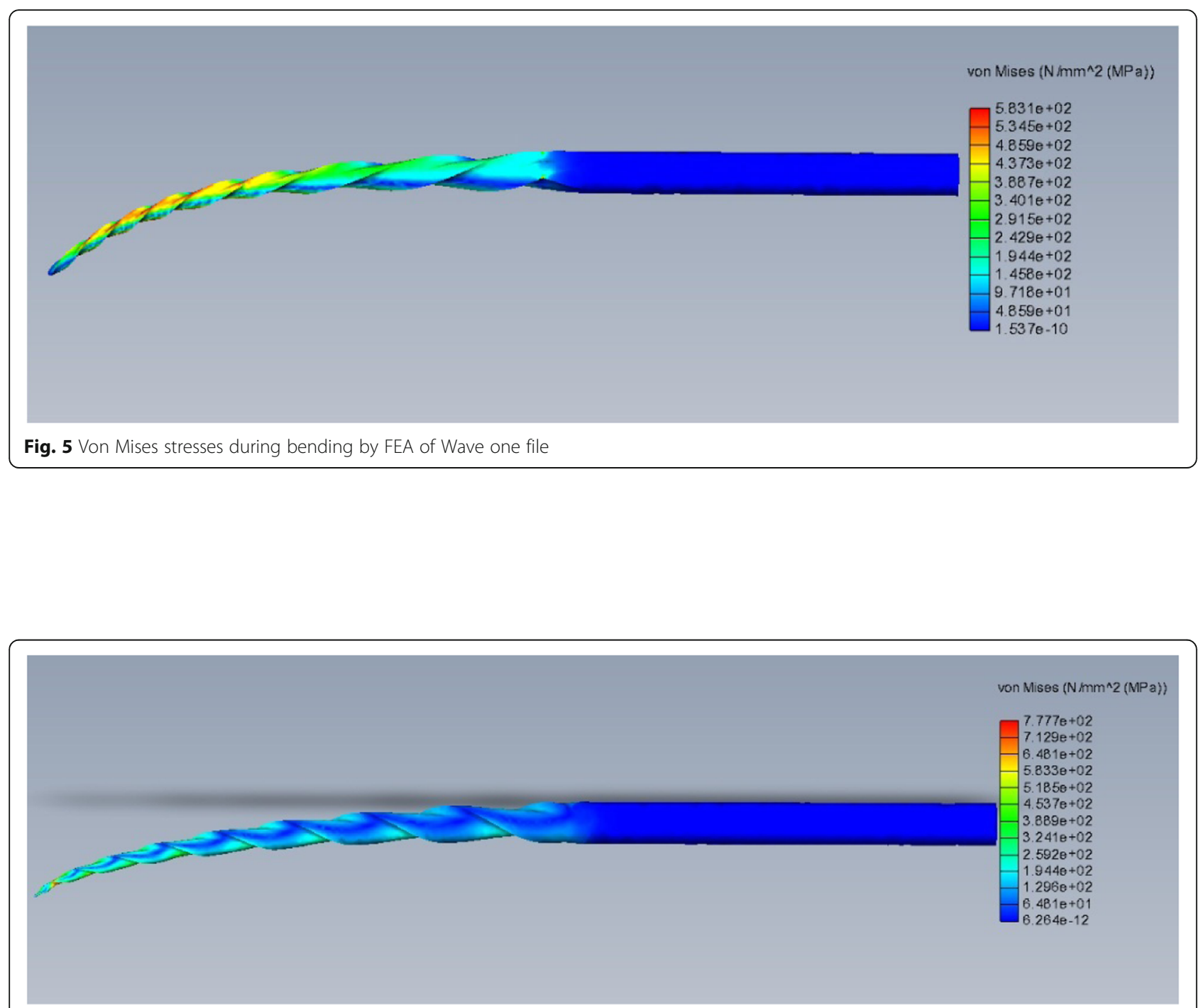

Fig. 6 Von Mises stresses during bending by FEA of Reciproc Blue file

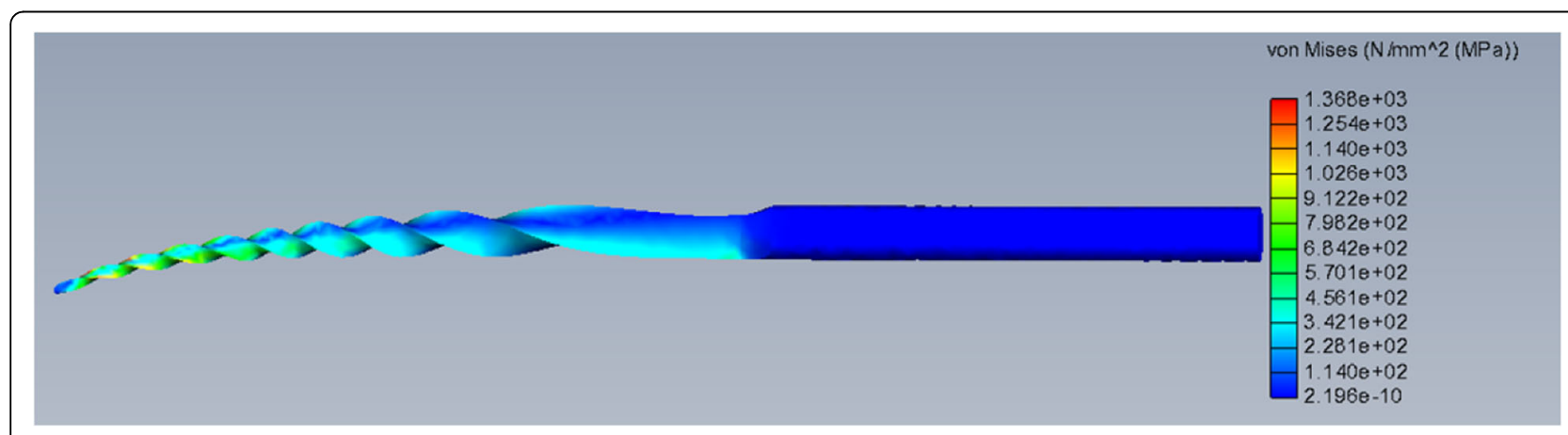

Fig. 7 Von Mises stresses during bending by FEA of One Shape file 


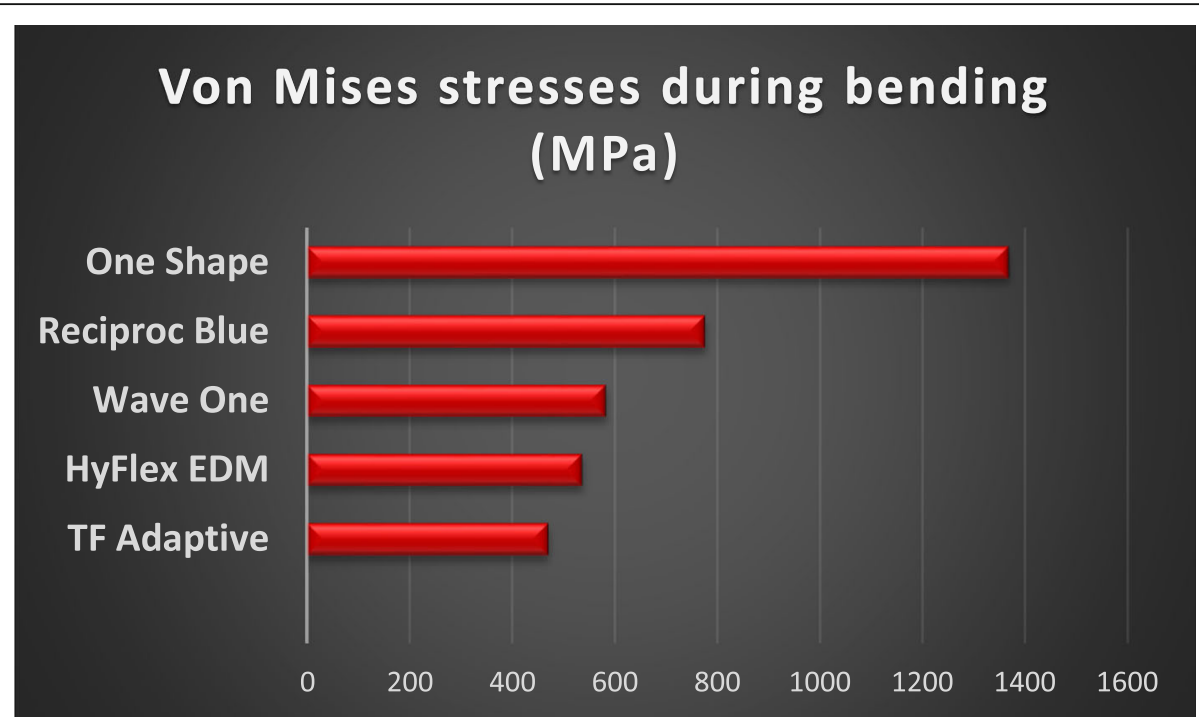

Fig. 8 Bar chart showing von Mises stresses among the different endodontic instruments

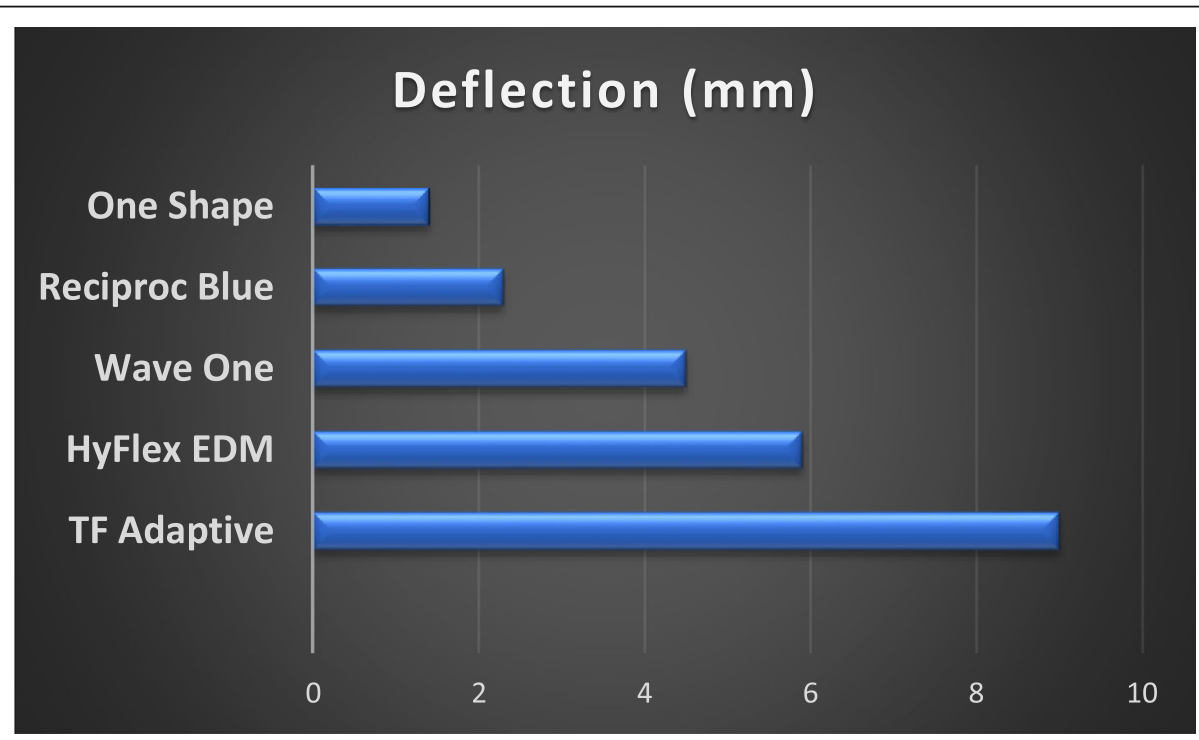

Fig. 9 Bar chart showing deflection among the different endodontic instruments

Table 3 The results of the laboratory cantilever bending test and numerical FEA during bending

\begin{tabular}{llll}
\hline $\begin{array}{l}\text { Endodontic } \\
\text { instrument }\end{array}$ & Laboratory test & Finite element analysis (FEA) & Deflection (mm) \\
\cline { 3 - 4 } & Cantilever bending load (g) & Von Mises stresses during bending (MPa) & 9 \\
\hline TF Adaptive & $86^{\mathrm{a}} \pm 0.1$ & 471 & 5.9 \\
HyFlex EDM & $99.8^{\mathrm{b}} \pm 0.5$ & 537 & 4.5 \\
Wave One & $144.5^{\mathrm{c}} \pm 0.4$ & 583 & 2.3 \\
Reciproc Blue & $155^{\mathrm{d}} \pm 0.8$ & 777 & 1.4 \\
One Shape & $174^{\mathrm{e}} \pm 0.4$ & 1368 & \\
& $P$ value & & $0.0001^{*}$
\end{tabular}




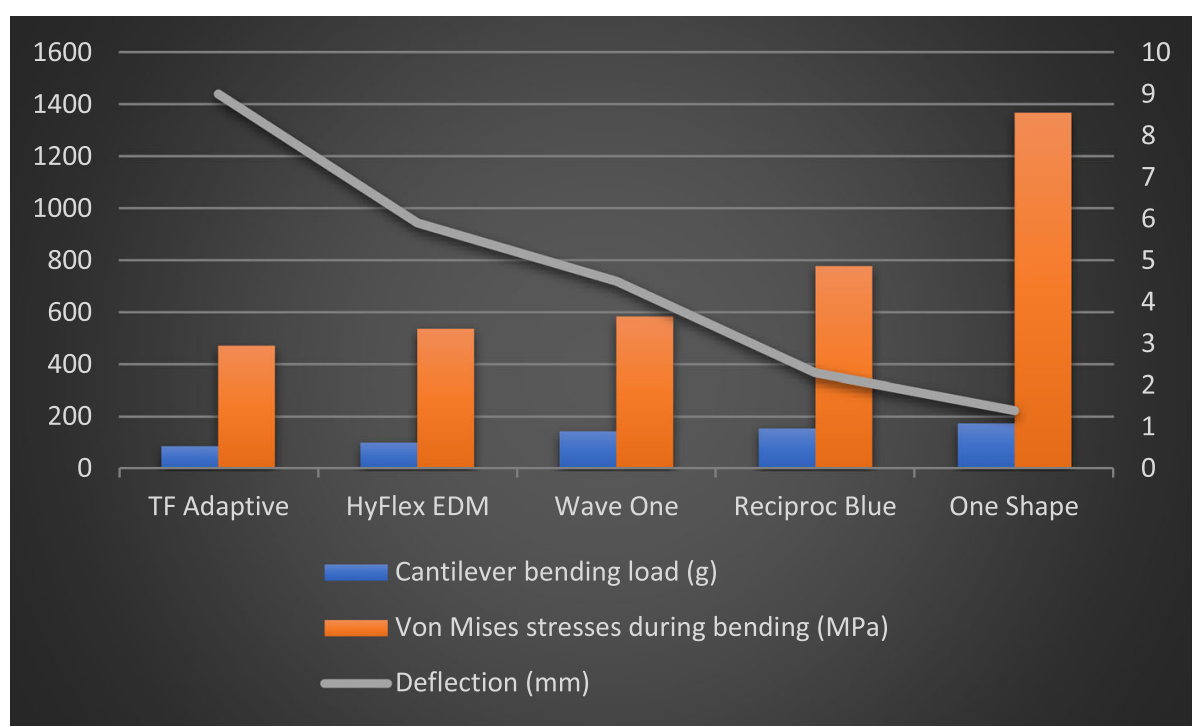

Fig. 10 Bar chart showing results of cantilever bending test, von Mises stress, and bending deflection during bending among the different endodontic instruments

\section{Abbreviations}

FEA: Finite element analysis; NiTi: Nickel-titanium; CT: Computerized tomography; 3D: Three-dimensional; 2D: Two-dimensional; CAD: Computer aided design; ANOVA: A one-way analysis of variance

\section{Acknowledgements}

Not applicable.

\section{Authors' contributions}

A. G. Ismail, M. Galal, M. H. Zaazou, T. M. Hamdy, and R. M. Abdelraouf contributed to the conception and design of the study, experimental work interpretation of the analyzed data, and writing the manuscript and revised and reviewed the draft manuscript. All authors have read and approved the manuscript.

\section{Funding}

The work was self-funded by the authors.

\section{Availability of data and materials}

All data generated or analyzed during this study are included in this published article.

\section{Ethics approval and consent to participate}

Not applicable.

\section{Consent for publication}

Not applicable.

\section{Competing interests}

The authors declare that they have no competing interests.

\section{Author details}

${ }^{1}$ Restorative and Dental Materials Department, National Research Centre (NRC), El Bohouth St., 12622 Dokki, Giza, Egypt. ${ }^{2}$ Biomaterials Department, Faculty of Dentistry, Cairo University, Cairo, Egypt.

Received: 29 July 2020 Accepted: 11 August 2020

Published online: 26 August 2020

\section{References}

Arbab-Chirani R, Chevalier V, Arbab-Chirani S, Calloch S. Comparative analysis of torsional and bending behavior through finite-element models of $5 \mathrm{Ni}-\mathrm{Ti}$ endodontic instruments. Oral Surg Oral Med Oral Pathol Oral Radiol Endod 2011;111(1):115-121.

Baek SH, Lee CJ, Versluis A, Kim BM, Lee W, Kim HC (2011) Comparison of torsional stiffness of nickel-titanium rotary files with different geometric characteristics. J Endod 37(9):1283-1286

De Arruda SL, De Azevedo Bahia MG, De Las Casas EB, Buono VTL (2013) Comparison of the mechanical behavior between controlled memory and superelastic nickel-titanium files via finite element analysis. J Endod 39(11): $1444-1447$

E. B, G. C, I. G, A. I. Comparative analysis of torsional and bending stresses in two mathematical models of nickel-titanium rotary instruments: ProTaper versus ProFile. J Endod [Internet]. 2003;29(1):15-9. Available from: http://www.embase. com/search/results?subaction=viewrecord\&from=export\&id=L36632495

Elnaghy AM, Elsaka SE (2015) Torsion and bending properties of OneShape and WaveOne instruments. J Endod 41(4):544-547

Fu HY, Wang FF, Hou XM (2019) Construction and mechanical analysis of finite element model for bending property of controlled memory wire nickeltitanium rotary file. Beijing Da Xue Xue Bao 51(1):131-135

Fukumori Y, Nishijyo M, Tokita D, Miyara K, Ebihara A, Okiji T (2018) Comparative analysis of mechanical properties of differently tapered nickeltitanium endodontic rotary instruments. Dent Mater J 37(4):667-674

Galal M, Hamdy TM (2020) Evaluation of stress distribution in nickel-titanium rotary instruments with different geometrical designs subjected to bending and torsional load: a finite element study. Bull Natl Res Cent 44(121):1-11

Galal M, Nassef T, Saber S, SE-A MZ (2015) Stress distribution of three NiTi rotary files under bending and torsional conditions using a Finite Element Analysis. Ain Shams Med J 7:1-8

Galal M, Ismail AG, Omar N, Zaazou M, Nassar MA (2019) Influence of thermomechanical treatment on the mechanical behavior of Protaper Gold versus Protaper Universal (a finite element study). Open Access Maced J Med Sci 7

Gao Y, Cheung GSP, Shen Y, Zhou X (2011) Mechanical behavior of ProTaper Universal F2 finishing file under various curvature conditions: a finite element analysis study. J Endod 37(10):1446-1450

Gavini G, Santos M dos, Caldeira CL, Machado ME de L, Freire LG, Iglecias EF, et al. Nickel-titanium instruments in endodontics: a concise review of the state of the art. Braz Oral Res [Internet]. 2018 Oct 18 [cited 2019 Aug 14]; 32(suppl 1). Available from: http://www.scielo.br/scielo.php?script=sci_ arttext\&pid=S1806-83242018000500602\&lng=en\&tlng=en

Hamdy TM, Galal M, Ismail AG, Abdelraouf RM. Evaluation of flexibility, microstructure and elemental analysis of some contemporary nickel-titanium rotary instruments. Open Access Maced J Med Sci. 2019 Oct;7(21). 
He R, Ni J (2010) Design improvement and failure reduction of endodontic files through finite element analysis: application to V-Taper file designs. J Endod 36(9):1552-1557

Jiang Q, Huang Y, Tu XR, Li Z, He Y, Yang X (2018) Biomechanical properties of first maxillary molars with different endodontic cavities: a finite element analysis. J Endod 44(8):1283-1288

Karova E. Lifespan of One Shape files used in severely curved canals in resin blocks and extracted teeth. Int J Sci Res [Internet]. 2015;4(1):1940-4. Available from: https://www.ijsr.net/archive/v4i1/SUB15719.pdf

Kim HC, Kim HJ, Lee CJ, Kim BM, Park JK, Versluis A (2009a) mechanical response of nickel-titanium instruments with different cross-sectional designs during shaping of simulated curved canals. Int Endod J 42(7):593-602

Kim TO, Cheung GSP, Lee JM, Kim BM, Hur B, Kim HC (2009b) Stress distribution of three NiTi rotary files under bending and torsional conditions using a mathematic analysis. Int Endod J 42(1):14-21

Lee MH, Versluis A, Kim BM, Lee CJ, Hur B, Kim HC (2011) Correlation between experimental cyclic fatigue resistance and numerical stress analysis for nickeltitanium rotary files. J Endod 37(8):1152-1157

Poly A, AlMalki F, Marques F, Karabucak B (2019) Canal transportation and centering ratio after preparation in severely curved canals: analysis by microcomputed tomography and double-digital radiography. Clin Oral Investig 23(12):4255-4262

Pongione G, Pompa G, Milana V, Di Carlo S, Giansiracusa A, Nicolini E, et al. Flexibility and resistance to cyclic fatigue of endodontic instruments made with different nickel-titanium alloys: a comparative test. Ann Stomatol (Roma) [Internet] 2012;3(3-4):119-22. Available from: http://www.ncbi.nlm.nih.gov/ pubmed/23386933\%0A, http://www.pubmedcentral.nih.gov/articlerender. fcgi?artid=PMC3555470

Sihivahanan D, Reddy TVK, Thomas AR, Senthilnathan N, Sivakumar M, Shivanna S (2017) Comparative evaluation of stress developed on rotary retreatment instruments during retrieval of gutta-percha. J Contemp Dent Pract 18(6): 484-489

Versluis A, Kim HC, Lee W, Kim BM, Lee CJ (2012) Flexural stiffness and stresses in nickel-titanium rotary files for various pitch and cross-sectional geometries. J Endod 38(10):1399-1403

Walid N (2017) Review and classification of heat treatment procedures of Niti instruments and its implication on files fatigue. J Dent Sci 2(2):1-19

Zaazou M, El-Anwar M, El-Zawahry M, Abou EM (2012) The effect of post materials on stress distribution on endodontically treated lower first premolar: finite element analysis study. Aust J Basic Appl Sci 6(12):492-498

Zhou H, Peng B, Zheng Y-F. An overview of the mechanical properties of nickeltitanium endodontic instruments. Endod Top. 2013;

\section{Publisher's Note}

Springer Nature remains neutral with regard to jurisdictional claims in published maps and institutional affiliations.

\section{Submit your manuscript to a SpringerOpen ${ }^{\circ}$ journal and benefit from:}

- Convenient online submission

- Rigorous peer review

- Open access: articles freely available online

High visibility within the field

- Retaining the copyright to your article

Submit your next manuscript at $\boldsymbol{\nabla}$ springeropen.com 